\title{
Mishti copes with diabetes: A pragmatic approach to coping skills training
}

\author{
Sanjay Kalra, Bharti Kalra ${ }^{1}$ \\ Departments of Endocrinology and ${ }^{1}$ Obstetrics, Bharti Hospital, Karnal, Haryana, India
}

I am Misthi. I am 4-year-old. I was born when the Changing Diabetes in Children (CDiC) programme began in India. I live with diabetes.

Living with diabetes is just like living with any person, any pet, or any other attribute. It is full of excitement and surprises, as well as unexpected happiness and satisfaction. However, it is also full of stresses and challenges. Coping with these issues requires special skills. These skills are known as coping skills or coping mechanisms. ${ }^{[1]}$

Coping skills are necessary not only for me, but also for my family and my health-care team. I sometimes remain anxious, depressed, or sad about my health. At other times, I feel confused about what to do. All these feelings are normal, provided I do not let them overwhelm me. I take these moods in my stride, and do not allow them to impact my professional (school) or personal (social) life.

My parents, sibling, and extended family members also have varied emotions regarding my diabetes. Their mood changes from time to time, depending on my health, the way in which my health-care team behaves with them, and what they hear or read about diabetes from other people or the media. My family, too, need to cope with all these stressors.

My health-care team, which includes my diabetes educators, doctors, and other staff, also faces challenges. They work

\begin{tabular}{|c|l|}
\hline \multicolumn{2}{|c|}{ Access this article online } \\
\hline Quick Response Code: & Website: \\
\hline & www.joshd.net \\
\hline & \\
\hline
\end{tabular}

round the clock to manage not only my biomedical problems, but also my psychosocial complaints. And, it is not only me that they look after, but also they care for hundreds of other children like me, along with their parents and siblings. Though they never complain (I do not know whom they would complain to, even if they wanted to), they do experience a certain amount of physical fatigue as well as mental and compassion fatigue. ${ }^{[2]}$ Therefore, they too need to learn coping skills.

Along with the other children and staff at our CDiC center, we have devised a simple method of learning and developing our coping skills. We call this the AEIOU method of Coping Skills Training [Table 1]. ${ }^{[3]}$ First, we assess ourselves and identify our predominant coping methods. We do this by talking to each other and listening to the things that we do. We talk about thoughts, words, behavior, and actions. We share what we think about diabetes, what we say or discuss about it, and how we behave in relation to diabetes care.

Once we have identified our coping mechanisms, we eliminate the negative ones and try to internalize the positive methods [Table 2]. Negative mechanisms include thinking all the time about diabetes, thinking in extreme (e.g., no one loves me because of sugar), blaming others (e.g., It is mummy's fault that I have poor control), or blaming oneself (e.g., I incurred sins in my past life, so I am unwell).

This is an open access article distributed under the terms of the Creative Commons Attribution-NonCommercial-ShareAlike 3.0 License, which allows others to remix, tweak, and build upon the work non-commercially, as long as the author is credited and the new creations are licensed under the identical terms.

How to cite this article: Kalra S, Kalra B. Mishti copes with diabetes: A pragmatic approach to coping skills training. J Soc Health Diabetes 2017;5:1-2.

Corresponding Author: Dr. Sanjay Kalra, Department of Endocrinology, Bharti Hospital, Karnal, Haryana, India.

E-mail: bridekarnal@gmail.com 
Table 1: Coping skills training for families with diabetes

Assess coping skills

Eliminate negative mechanisms

Internalize positive mechanisms

Observe on ongoing basis

Upgrade understanding

\section{Table 2: Coping skills in families with diabetes}

\begin{tabular}{lll}
\hline Negative & Neutral & Positive \\
\hline Think bad thoughts & Acceptance & Put in perspective \\
Think extreme thoughts & & Positive inside condition \\
Blame one self & & Pleasant thoughts \\
Blame others & & Plan for future \\
\hline
\end{tabular}

The key to shift from negative coping to a positive mode is acceptance. Once we accept what we are, who we are, and how we are, we can easily begin practicing the positive means of coping. All the four positive coping skills that we have listed start with the letter P. This makes them easy to remember; put diabetes in perspective (e.g., diabetes is just one part of my multifaceted life); find a positive side to your condition (e.g., diabetes helps me practice selfdiscipline); think pleasant thoughts (e.g., let us go for a vacation; I can take my insulin with me); and plan for the future (e.g., let me save money to buy a new glucometer).
Learning the 4Ps is just part of the process of coping skills training. Once we have understood these, we begin to implement them in our daily life. We use these skills not only in relation to diabetes, but for every sphere of life. The next steps that we follow are to observe ourselves (and our friends) on an ongoing basis and try to upgrade our understanding of coping skills training (CST). We do this by sharing this knowledge with others. We share both information and examples of coping skills so that we can become better masters of diabetes.

I am Mishti. I cope with diabetes. I cope well. How do you cope with your condition? Please let me know. We will share best practices with friends across the country.

\section{REFERENCES}

1. Kalra S, Kalra B, Batra P. Patient motivation for insulin/ injectable therapy: The karnal model. Int J Clin Cases Investig 2010;1:11-5.

2. Bhutani J, Bhutani S, Balhara YP, Kalra S. Compassion fatigue and burnout amongst clinicians: a medical exploratory study. Indian J Psychol Med 2012;34:332-7.

3. Kalra S, Kalra B, Sharma A, Sirka M. Coping skills training: The AEIOU approach. Endocr J 2010;57 Suppl 2:S391. 